\title{
Anaphylaxis Induced by a Drug Containing Lysozyme and Papain: Influence of Papain on the IgE Response
}

\author{
Sara Benedéa Inmaculada Pérez-Rangel ${ }^{b}$ Daniel Lozano-Ojalvo ${ }^{a} \quad E^{2}$ Ena Molina ${ }^{a}$ \\ María Dolores Ibañez ${ }^{b}$ Rosina López-Fandiño ${ }^{a} \quad$ Iván López-Expósitoa

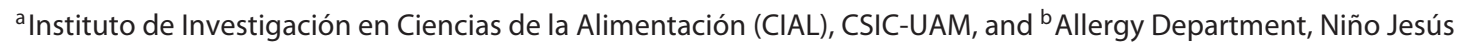 \\ University Hospital, Madrid, Spain
}

\section{Key Words}

Anaphylaxis · Egg allergy · Lysozyme · Oral immunotherapy · Papain

\begin{abstract}
Background: This paper reports the case of an egg-allergic pediatric patient who, once desensitized to egg following a successful rush oral immunotherapy protocol, could also tolerate Lizipaina ${ }^{\circledR}$, a drug containing lysozyme (LYS) and papain, which had previously caused him a severe allergic reaction. Because the LYS amount that elicited the anaphylactic reaction $(5 \mathrm{mg}$ ) was much lower than that tolerated during a double-blind placebo-controlled food challenge (corresponding to approximately $60 \mathrm{mg}$ of LYS), the possibility that the presence of papain could increase the allergenic potential of LYS was investigated. Methods: Lizipaina, LYS and LYS hydrolyzed with papain were analyzed by SDS-PAGE under reducing and nonreducing conditions, and Western blotting of sera from egg-allergic patients was performed in order to detect IgE-binding fragments. Finally, sequence identification of the IgE-reactive bands was carried out by MALDI-TOF/TOF. Results: The SDS-PAGE pattern of LYS treated with papain under nonreducing conditions showed the presence of intact LYS that partially disappeared follow-
\end{abstract}

ing reduction with $\beta$-mercaptoethanol, releasing IgE-reactive fragments as determined by Western blotting. MALDITOF/TOF revealed that papain degraded LYS, giving rise to three IgE-binding fragments: LYS (22-129), LYS (34-96) and LYS (62-128) that likely remained linked through the disulfide bonds present in the LYS molecule. Conclusion: The combined administration of LYS with proteolytic enzymes such as papain may have developed a severe allergic reaction in the patient studied, underlining the importance of considering all the components and their interactions when drugs are to be consumed by allergic persons.

๑) 2014 S. Karger AG, Basel

\section{Introduction}

Lysozyme (LYS), which is present in milk from different species and in many biological fluids and tissues, is broadly used by virtue of its potent bactericidal effect, which is partially based on its lytic activity on the cell wall of Gram-positive microorganisms [1]. Hen egg, which contains $1-3 \mathrm{~g} / \mathrm{l}$ of LYS, is probably one of the main

\section{S.B. and I.P.-R. contributed equally to this work.}

\section{KARGER}

E-Mail karger@karger.com

www.karger.com/iaa (c) 2014 S. Karger AG, Basel

$1018-2438 / 14 / 1652-0083 \$ 39.50 / 0$
Correspondence to: Dr. Iván López-Expósito

Instituto de Investigación en Ciencias de la Alimentación (CIAL) CSIC-UAM C/Nicolás Cabrera 9

ES-28049 Madrid (Spain)

E-Mail ivan.lopez@csic.es 
sources of LYS used to maintain the quality of food and pharmaceutical products. However, hen eggs are also the second most frequent cause of food allergy in infants, with LYS being one of its main allergens (Gal d 4) responsible for a sensitization frequency of more than $35 \%$ in patients with clinically observed egg hypersensitivity $[2,3]$.

LYS of egg origin is being increasingly used as an antibacterial additive to prevent spoilage of cheese, wine or other foodstuff $[4,5]$, as well as in medicinal products for respiratory tract infections and congestions, which do not usually declare its source [6], thus posing a risk for consumers allergic to hen egg. Hypersensitivity reactions to drugs containing LYS have been described that, in some cases, happen to occur in children that had never intentionally eaten egg and either ignore they are sensitized to egg proteins or react at the first ingestion $[7,8]$.

This work reports a severe allergic reaction to Lizipai$\mathrm{na}^{\circledR}$, a drug used for the symptomatic relief of mild infections of the throat and mouth which contains $5 \mathrm{mg}$ of LYS, in a patient able to tolerate a much greater amount of LYS as part of egg white. In addition to LYS, Lizipaina contains papain ( $2 \mathrm{mg}$ ) and bacitracin ( $3 \mathrm{mg})$. Papain is a cysteine proteinase allergen, such as bromelain and Der $\mathrm{p} 1$, whose intrinsic proteolytic activity has been associated to its capacity to induce Th2-mediated allergic responses [9]. This study investigates a possible role for papain in increasing the allergenicity of LYS through the release of IgE-binding degradation products. Besides, successful LYS desensitization by egg oral immunotherapy (EOIT) is described.

\section{Materials and Methods}

\section{Ethics Statement}

All human samples and procedures were obtained/performed with written consent from the next of kin, caretakers or guardians on behalf of the minors/children involved in the study. The Bioethics Committees from the CSIC (Consejo Superior de Investigaciones Científicas) and the Hospital Infantil Universitario Niño Jesús approved all experiments.

\section{Patient}

A 15-year-old boy, diagnosed with persistent allergy to egg, fish and tree nuts, atopic dermatitis and allergic asthma developed pharyngeal itching, dysphonia, dysphagia and bronchospasm $15 \mathrm{~min}$ after taking a tablet of Lizipaina (5 mg LYS, $3 \mathrm{mg}$ bacitracin and $2 \mathrm{mg}$ papain) due to a mild respiratory viral infection. These symptoms were controlled with intramuscular epinephrine, intravenous antihistamines and corticosteroids at the emergency unit. The boy had never eaten egg since his first allergic reaction at the age of 1 year. Because of his persistent egg allergy and the risk of severe reactions due to accidental ingestion of egg proteins, the patient was subjected to EOIT.

\section{Egg Oral Immunotherapy}

In order to determine the starting dose of EOIT, the patient underwent a double-blind placebo-controlled food challenge (DBPCFC) with dehydrated egg white (OVO-DES NM, Madrid, Spain) [10]. Administration of 8 doses $(4,20,50,110,225,450,900$ and $1,800 \mathrm{mg}$ ) in $50 \mathrm{ml}$ of soy milk shake with chocolate was scheduled every $20 \mathrm{~min}$ (corresponding to an accumulated dose of, approximately, 3,600 $\mathrm{mg}$, equivalent to $43 \mathrm{ml}$ of a whole egg white) until symptom development. Milk shake without egg was used as placebo.

The patient underwent a rush EOIT protocol with OVO-DES at the Allergy Day Unit under the direct supervision of medical and nursing staff. A build-up schedule was performed daily, starting with the last tolerated dose in the DBPCFC. The corresponding doses were administered in sweetened orange juice $1 \mathrm{~h}$ apart $(900$ and $1,800 \mathrm{mg}$ on the 1 st day; 1,800 and 3,600 $\mathrm{mg}$ on the 2 nd day), with a final observation after $2 \mathrm{~h}$. In the maintenance phase, the patient took 3,600 mg daily at home during the 1st week and, thereafter, 1 undercooked egg was introduced in the patient's diet every $48 \mathrm{~h}$.

An open oral challenge with a tablet of Lizipaina was carried out 45 days following the build-up phase of EOIT. Increasing amounts of Lizipaina were administered every $30 \mathrm{~min}$ in 3 doses $(1 / 4,1 / 4$ and $1 / 2$ of a tablet $)$ to achieve the therapeutic dose.

\section{Skin Tests}

Skin prick tests (SPT) with commercial extracts of egg, egg white, ovalbumin (OVA) and ovomucoid (OVM), histamine phosphate and saline solution (Leti Laboratories, Madrid, Spain) were conducted according to standard procedures [11] before EOIT $\left(\mathrm{T}_{0}\right)$, and $15\left(\mathrm{~T}_{1}\right)$ and 45 days $\left(\mathrm{T}_{2}\right)$ after the build-up phase. Prick tests were also performed with Lizipaina in saline as vehicle ( 1 tablet dissolved in $1 \mathrm{ml}$ ). Three nonallergic controls were tested with the same preparation of Lizipaina to exclude nonspecific reactions.

Serum Antibodies

Serum total IgE, serum specific IgE to egg, egg white, OVA, OVM and LYS, and serum specific IgG4 to egg white, OVA and OVM were measured by the ImmunoCAP System (Phadia, Uppsala, Sweden) at $\mathrm{T}_{0}, \mathrm{~T}_{1}$ and $\mathrm{T}_{2}$.

\section{SDS-PAGE and Western Blotting}

For SDS-PAGE and Western blotting, LYS (L2879, chloride form from chicken egg white grade VI, 60,000 U/mg protein, EC 3.2.1.17; Sigma-Aldrich, St. Louis, Mo., USA) and Lizipaina were used at an equivalent LYS concentration. In addition, LYS was hydrolyzed with papain (76218, papain from Carica papaya, $12 \mathrm{U} /$ mg, EC 232.627.2; Sigma) at an enzyme:substrate ratio of $2: 5$ (w:w), as in Lizipaina, for $3 \mathrm{~h}$ at $54^{\circ} \mathrm{C}$, and the reaction was stopped by heating at $100^{\circ} \mathrm{C}$ for $10 \mathrm{~min}$.

Samples were diluted in $62.5 \mathrm{~mm}$ Tris- $\mathrm{HCl}$ buffer containing $10 \%(\mathrm{v} / \mathrm{v})$ glycerol and $2 \%(\mathrm{w} / \mathrm{v})$ SDS or tricine sample buffer (BioRad, Richmond, Calif., USA), without or with $5 \%(\mathrm{v} / \mathrm{v}) \beta$ mercaptoethanol ( $\beta$-ME; nonreducing and reducing conditions, respectively) and heated at $95^{\circ} \mathrm{C}$ for $4 \mathrm{~min}$. Samples were analyzed on precast Criterion XT 12\% Bis-Tris or $16.5 \%$ Tris-tricine gels, 
and electrophoretic separations were carried out at 150 or $100 \mathrm{~V}$, using XT-MES or Tris-tricine as running buffers (Bio-Rad), respectively, in the Criterion cell (Bio-Rad). Gels were stained with Bio-Safe Coomassie G-250 (Bio-Rad).

After SDS-PAGE separation, the gels were soaked in transfer buffer (48 mM Tris, 39 mM glycine, 20\% methanol, $\mathrm{pH} 9.2$ ) for 20 min and subjected to semidry transfer in a Trans-Blot SD (Bio$\mathrm{Rad}$ ) for $20 \mathrm{~min}$ at $18 \mathrm{~V}$. Then, $0.22-\mu \mathrm{m}$ nitrocellulose membranes were developed according to Martos et al. [12]. Sera from the above-described patient were used at different time points before and after EOIT, as well as individual serum samples from 5 children with proven allergy to egg proteins, diagnosed on the basis of clinical allergic symptoms of an acute reaction after egg ingestion, together with evidence of high LYS-specific IgE antibodies (from 0.59 to $266 \mathrm{kU} / \mathrm{l}$ ) and a pool of 6 sera (on average $0.38 \mathrm{kU} / 1 \mathrm{LYS}$ specific $\operatorname{IgE})$.

MALDI-TOF/TOF Analyses of the Immunoreactive Bands

The identification of the sequence of the IgE-binding LYS fragments of the Lizipaina sample was carried out by mass fingerprinting and MALDI-TOF/TOF analysis of its tryptic digests, in combination with intact molecular weight determination. Analyses were performed on an Autoflex Speed ${ }^{\mathrm{TM}}$ (Bruker Daltonic, Bremen, Germany) as described [13].

\section{Results}

\section{Egg Oral Immunotherapy}

During the DBPCFC, the patient developed immediate oral allergy symptoms and long-lasting abdominal pain, pyrosis and diarrhea $1 \mathrm{~h}$ after taking the 1,800-mg dose (which corresponded to an accumulated dose of approximately $3,600 \mathrm{mg}$ ) with spontaneous clinical resolution.

EOIT was carried out without clinical incidence in just 2 days $(900+1,800 \mathrm{mg}$ on the 1 st day and $1,800+3,600$ $\mathrm{mg}$ on the 2 nd day). The patient referred only 3 episodes of limited adverse reactions during the first 45 days of maintenance: the oral allergy syndrome after administration of a single 3,600-mg dose and after eating an omelet, and ocular pruritus after eating meringue. The controlled open oral challenge with Lizipaina was conducted 45 days following the build-up phase of EOIT showing good tolerance.

\section{Skin Tests and Serum Antibodies}

The results of the SPT, serum total and specific IgE, and serum specific IgG4 to different egg protein fractions are shown in table 1. All SPT decreased markedly at $\mathrm{T}_{1}$, but the SPT with Lizipaina in saline increased and remained high at the end of the study.

Serum IgE specific to whole egg, egg white and, particularly, to LYS continuously increased during the time
Table 1. Results of the in vivo and in vitro tests performed on the egg-allergic patient submitted to EOIT at different evaluation times

\begin{tabular}{lrrr}
\hline & $\mathrm{T}_{0}$ & $\mathrm{~T}_{1}$ & $\mathrm{~T}_{2}$ \\
\hline SPT (d + D/2), mm ${ }^{\mathrm{a}}$ & & & \\
Egg & 5 & 4 & 4 \\
Egg white & 8 & 3 & 2 \\
OVA & 5 & 2 & 4 \\
OVM & 10 & 3 & 4 \\
Prick test with Lizipaina in saline, mm & 6 & 8 & 8 \\
Serum total IgE, IU/ml & 661 & 792 & 609 \\
Serum-specific IgE, kU/ml & & & \\
$\quad$ Egg & 5.95 & 5.25 & 6.88 \\
Egg white & 4.72 & 5.37 & 6.65 \\
OVA & 0.76 & 0.45 & 0.57 \\
OVM & 0.92 & 1.28 & 1.33 \\
LYS & 4.87 & 8.59 & 11.3 \\
Serum-specific IgG4, mg/ml & & & \\
Egg white & 2.37 & 16.4 & 23.6 \\
OVA & 1.79 & 16.4 & 25 \\
OVM & 0.66 & 4.46 & 6.49 \\
\hline
\end{tabular}

a Positive if wheal diameter $\geq 3 \mathrm{~mm}$.

period considered. Serum-specific IgG4 also increased, with the highest levels being detected to OVA and egg white at $\mathrm{T}_{2}$.

\section{Reactivity of IgE from Egg-Allergic Patients towards} LYS and Lizipaina

Western blotting of LYS, Lizipaina and egg white was conducted following SDS-PAGE under reducing conditions with sera from the allergic patient at $\mathrm{T}_{0}, \mathrm{~T}_{1}$ and $\mathrm{T}_{2}$ (fig. 1). Before EOIT, the patient's serum was reactive towards the main egg white proteins (fig. 1b, lane 3). LYS, with a molecular mass of $14.3 \mathrm{kDa}$, was strongly recognized by the serum, both as pure protein (fig. $1 \mathrm{~b}$, lane 1 ) and as part of the egg white (fig. 1b, lane 3). In the Lizipaina sample, there were IgE-reactive bands corresponding to papain (approximately $23 \mathrm{kDa}$ ), LYS and lower molecular mass peptides (fig. 1b, lane 2). Bacitracin, another component of Lizipaina, a $1.4-\mathrm{kDa}$ antibiotic peptide, is too small to be resolved and retained in the polyacrylamide gel. The reactivity of IgE from the patient's sera towards the main egg proteins, including LYS, was maintained along immunotherapy (fig. 1c, d).

The possibility that the lower molecular mass IgEbinding bands were released from LYS via papain was tested in an experiment where LYS was incubated with 
Fig. 1. SDS-PAGE (a) and Western blotting (b-d) with serum from a patient submitted to rush EOIT at $\mathrm{T}_{0}-\mathrm{T}_{2}$ of the buildup phase (table 1) of $0.25 \mathrm{mg} / \mathrm{ml} \mathrm{LYS} \mathrm{(lane}$ 1); Lizipaina (0.25 mg LYS/ml; lane 2), and raw egg white $(0.34 \mathrm{mg} \mathrm{LYS} / \mathrm{ml}$; lane 3$)$, all dissolved in sample buffer with reducing agent. Electrophoresis was conducted using Bis-Tris $12 \%$ acrylamide gels. $\mathrm{M}=\mathrm{Mo}$ lecular mass marker (Precision Plus Protein standards; Bio-Rad) ranging from 10 to $250 \mathrm{kDa}$.

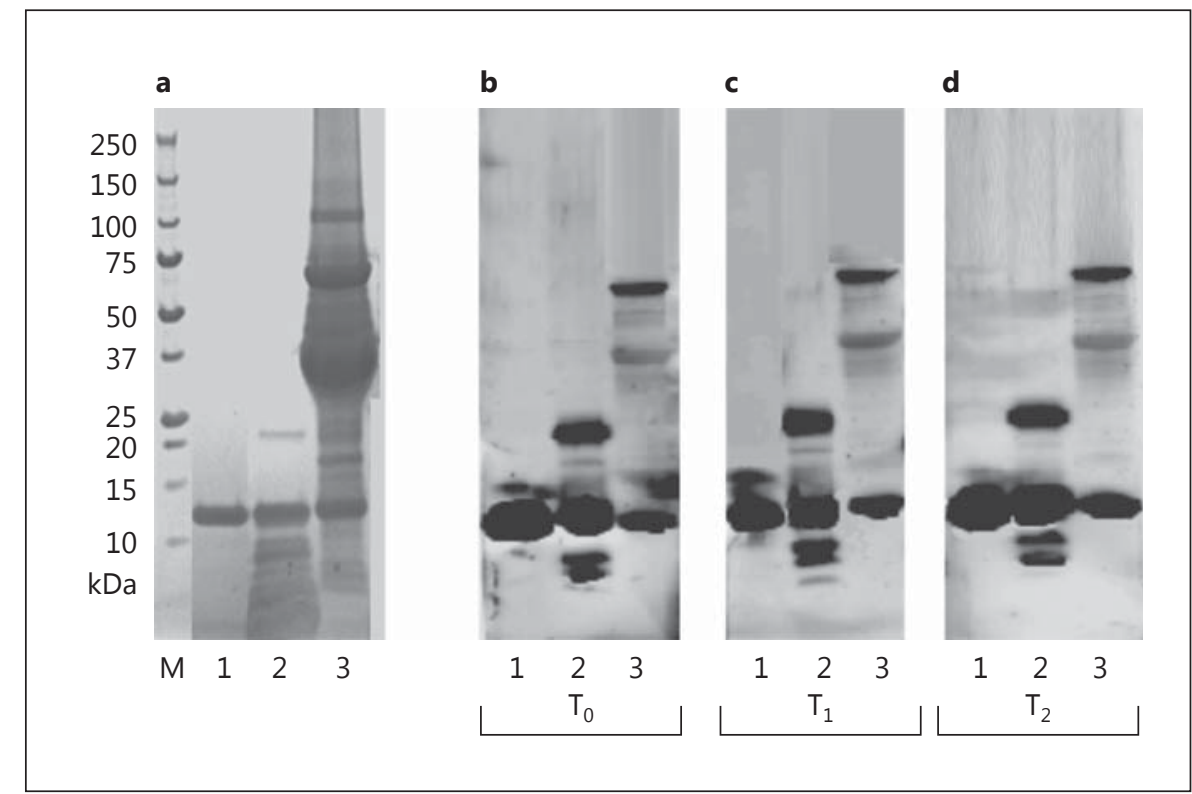

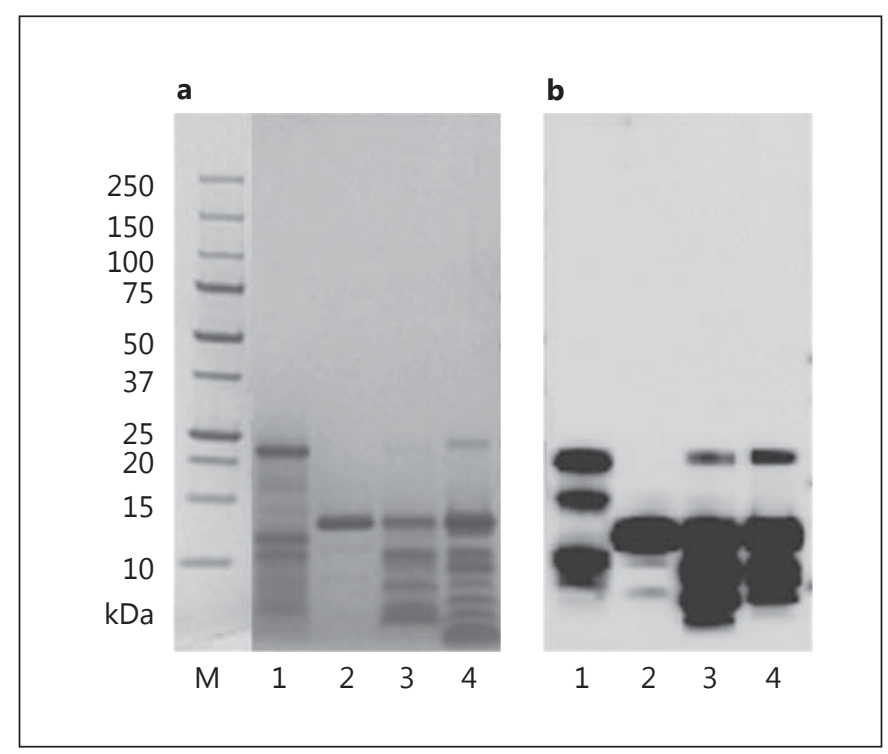

Fig. 2. SDS-PAGE (a) and Western blotting (b) with serum from the patient submitted to rush EOIT at $\mathrm{T}_{2}$ of the build-up phase (table 1$)$ of papain $(0.5 \mathrm{mg} / \mathrm{ml}$; lane 1$)$; LYS $(0.42 \mathrm{mg} / \mathrm{ml}$; lane 2$)$; LYS hydrolyzed with papain at $54^{\circ} \mathrm{C}$ for $3 \mathrm{~h}(0.42$ and $0.17 \mathrm{mg} / \mathrm{ml}$, respectively; lane 3$)$, and Lizipaina ( $0.5 \mathrm{mg} \mathrm{LYS} / \mathrm{ml}$; lane 4$)$, all dissolved in sample buffer with reducing agent. Electrophoresis was conducted using Bis-Tris 12\% acrylamide gels. $\mathrm{M}=$ Molecular mass marker (Precision Plus Protein standards; Bio-Rad) ranging from 10 to $250 \mathrm{kDa}$. papain for $3 \mathrm{~h}$ at $54^{\circ} \mathrm{C}$. Under reducing conditions, SDSPAGE showed that papain hydrolyzed LYS, which resulted in lower molecular mass fragments (fig. 2a, lane 3), which were to a great extent coincident with the bands present in the Lizipaina sample (fig. 2a, lane 4). According to the Western blot with serum at $\mathrm{T}_{2}$, depicted in figure $2 \mathrm{~b}$, these bands strongly bound IgE (fig. 2b, lanes 3 , 4 ). On the other hand, papain gave, in addition to the 23$\mathrm{kDa}$ band, two other IgE-binding bands of $\sim 15$ and $\sim 10$ $\mathrm{kDa}$ (fig. 2b, lane 1).

Sera from 5 egg-allergic patients were analyzed for IgE binding to LYS, papain and LYS treated with papain, and electroblotted following SDS-PAGE with and without $\beta$-ME (fig. 3). Comparison between the SDS-PAGE patterns under reducing and nonreducing conditions showed that the degradation products produced by papain hydrolysis on LYS were only visible after reduction of the disulfide bonds of the protein (fig. 3a). All the allergic donors exhibited IgE reactivity to LYS, but varied in their reactivity to the bands released by the papain action under reducing conditions (fig. 3b, f), which did not seem to depend on the levels of total serum or LYS-specific IgE, except for the patient with the highest titer (266 $\mathrm{kU} / \mathrm{ml}$ ), who exhibited a very strong reaction (fig. $3 \mathrm{f}$ ). Unexpectedly, sera from nonallergic patients also showed a weak binding to LYS bands (fig. 3g). This binding seemed to be unspecific as LYS-specific IgE was not detected by both ImmunoCAP and competitive ELISA assays with nonallergic sera (data not shown). All the sera 


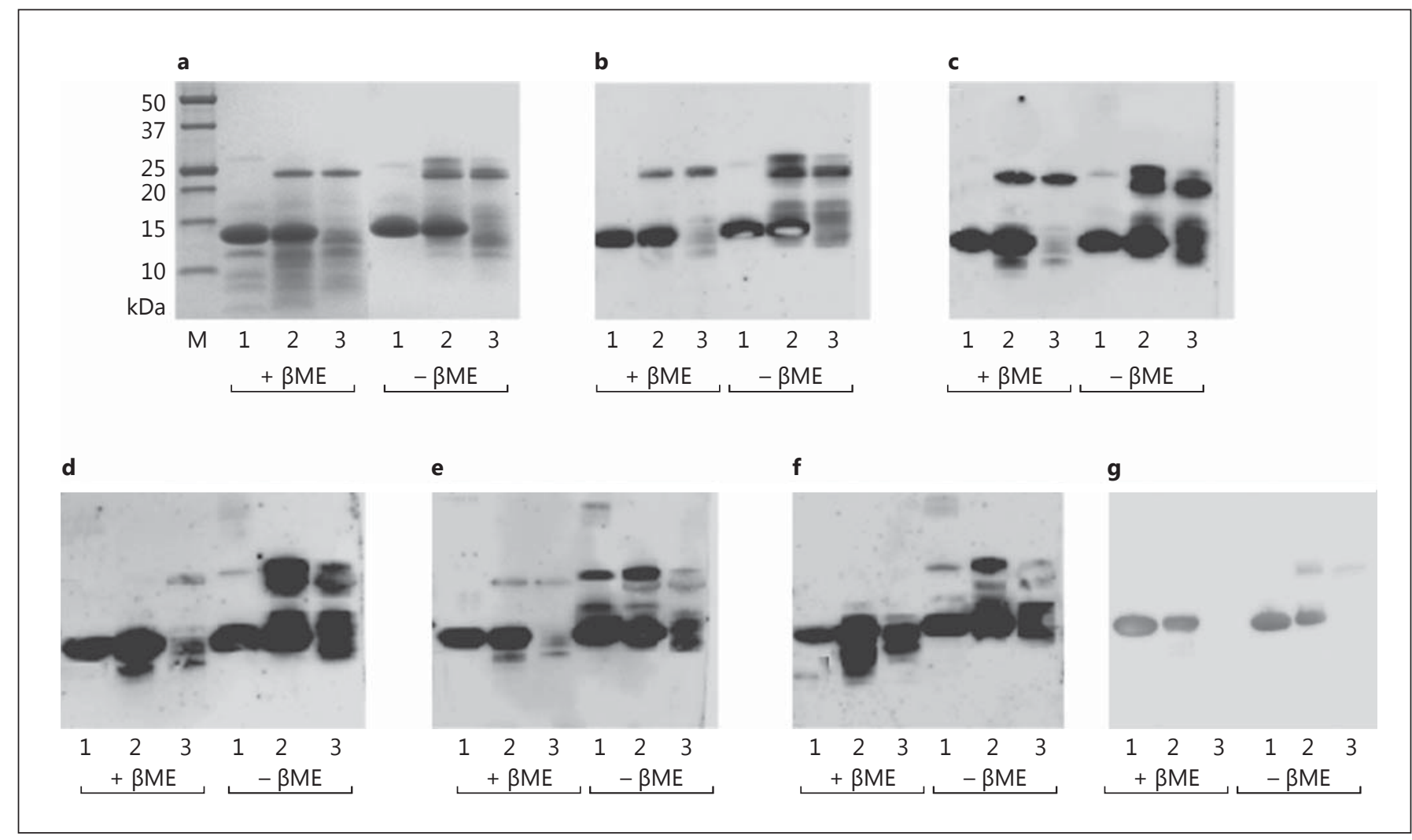

Fig. 3. SDS-PAGE (a) and Western blotting (b-f) with sera from 5 egg-allergic patients with $1.13(\mathbf{b}), 35.7$ (c), 0.59 (d), $36.6(\mathbf{e})$ and $266 \mathrm{kU} / 1$ of LYS-specific IgE (f) and from 1 nonallergic donor $(\mathbf{g})$ of LYS $(0.6 \mathrm{mg} / \mathrm{ml}$; lane 1$)$; LYS hydrolyzed with papain at $54^{\circ} \mathrm{C}$ for $3 \mathrm{~h}(0.6$ and $0.25 \mathrm{mg} / \mathrm{ml}$, respectively; lane 2$)$, and papain $(0.25$ $\mathrm{mg} / \mathrm{ml}$; lane 3), all dissolved in sample buffer with $(+\beta \mathrm{ME})$ and without $(-\beta \mathrm{ME})$ reducing agent. Electrophoresis was conducted using Bis-Tris $12 \%$ acrylamide gels. $\mathrm{M}=$ Molecular mass marker (Precision Plus Protein standards; Bio-Rad) ranging from 10 to $250 \mathrm{kDa}$. also recognized nonreduced and reduced papain bands, albeit with different intensity.

SDS-PAGE analysis of Lizipaina was also performed under nonreducing and reducing conditions using a polyacrylamide gel specific to resolve low molecular mass bands, followed by Western blot (fig. 4). This confirmed that in the nonreduced sample of Lizipaina, only a band of intact LYS was present, but when the sample was reduced with $\beta$-ME before SDS-PAGE, the band of intact LYS decreased and several degradation products were released (fig. 4a), including two IgE-binding fragments of a molecular mass $>6,500 \mathrm{Da}$ (fig. $4 \mathrm{~b}$ ). To identify the LYS fragments that contributed to IgE binding, both immunoreactive bands were subjected to in-gel tryptic digestion as well as intact molecular weight determination by MALDI-TOF/TOF (table 2). The higher molecular mass band, with an estimated mass of $11,869.889$, corresponded to LYS (22-129) (molecular mass 11,887.641). The lower molecular mass band contained two different products (with estimated masses of 7,220 and 7,394) that corresponded to LYS (34-96) (molecular mass 6,892) and LYS (62-128) (molecular mass 7,380), respectively. Cleavage at $\operatorname{Arg}_{21}, \mathrm{Lys}_{33}, \operatorname{Arg}_{68}, \operatorname{Arg}_{61}, \mathrm{Lys}_{96}$ and $\operatorname{Arg}_{128}$ is consistent with papain specificity, which prefers to cleave at the C-terminal side of Arg or Lys, N-linked to a hydrophobic amino acid residue.

\section{Discussion}

We report a case of a boy suffering from egg allergy who, once desensitized to egg following a rush EOIT, could also tolerate a LYS-containing drug which had previously caused him a severe anaphylactic reaction, which indicates the effectiveness of the rapid oral desensitization protocol used. Successful immunotherapy is associ- 
Table 2. LYS fragments identified by MALDI-TOF/TOF after in-gel tryptic digestion of the IgE-binding fragments of Lizipaina following SDS-PAGE under reducing conditions (marked as bands 1 and 2 in fig. 4)

\begin{tabular}{|c|c|c|c|}
\hline $\begin{array}{l}\text { Identified } \\
\text { fragment }\end{array}$ & $\begin{array}{l}\text { Tryptic peptide } \\
\text { (ion mass) }\end{array}$ & $\begin{array}{l}\text { Protein } \\
\text { residues }\end{array}$ & Sequence \\
\hline \multicolumn{4}{|l|}{$B A N D 1$} \\
\hline \multirow[t]{10}{*}{$22-129$} & $1,324.525$ & $22-33$ & GYSLGNWVCAAK 9: C \\
\hline & $1,427.631$ & $34-45$ & FESNFNTQATNR \\
\hline & $1,752.819$ & $46-61$ & NTDGSTDYGILQINSR \\
\hline & 992.361 & $62-68$ & WWCNDGR 3: C \\
\hline & $2,506.992$ & $74-96$ & NLCNIPCSALLSSDITASVNCAK 3: C; 7: C; 21: C \\
\hline & $1,816.992$ & $97-112$ & KIVSDGNGMNAWVAWR 9: oxidation \\
\hline & $1,691.775$ & $98-112$ & IVSDGNGMNAWVAWR 8: oxidation \\
\hline & $1,675.783$ & $98-112$ & IVSDGNGMNAWVAWR \\
\hline & 901.499 & $106-112$ & NAWVAWR \\
\hline & $1,044.513$ & $117-125$ & GTDVQAWIR \\
\hline \multicolumn{4}{|l|}{$B A N D 2$} \\
\hline \multirow[t]{4}{*}{$34-96$} & $1,427.734$ & $34-45$ & FESNFNTQATNR \\
\hline & $1,752.961$ & $46-61$ & NTDGSTDYGILQINSR \\
\hline & 992.445 & $62-68$ & WWCNDGR 3: C \\
\hline & $2,504.835$ & $74-96$ & NLCNIPCSALLSSDITASVNCAK 3: C; 7: C; 21: C \\
\hline \multirow[t]{4}{*}{$62-128$} & 992.445 & $62-68$ & WWCNDGR 3: C \\
\hline & $2,504.835$ & $74-96$ & NLCNIPCSALLSSDITASVNCAK 3: C; 7: C; 21: C \\
\hline & $1,674.904$ & $98-112$ & IVSDGNGMNAWVAWR \\
\hline & $1,044.61$ & $117-125$ & GTDVQAWIR \\
\hline
\end{tabular}

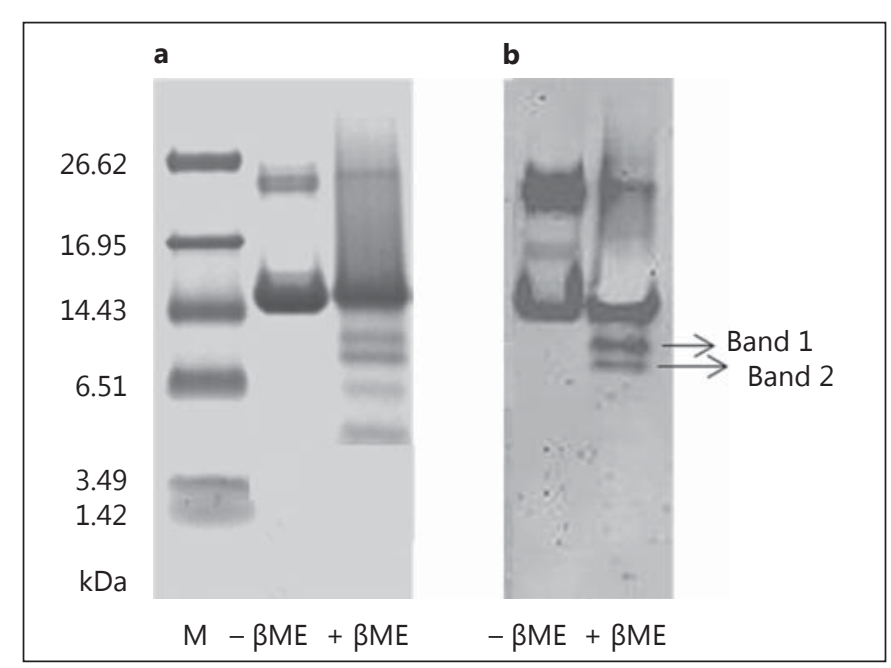

Fig. 4. SDS-PAGE (a) and Western blotting (b) with a pool of sera from 6 allergic patients with average LYS-specific IgE levels of 0.38 $\mathrm{kU} / \mathrm{l}$ of Lizipaina (1.25 $\mathrm{mg} \mathrm{LYS} / \mathrm{ml})$ dissolved in sample buffer without $(-\beta \mathrm{ME})$ and with $(+\beta \mathrm{ME})$ reducing agent. Electrophoresis was conducted using Tris-tricine $16.5 \%$ acrylamide gels. $\mathrm{M}=\mathrm{Mo}$ lecular mass marker (Precision Plus Protein Kaleidoscope standards; Bio-Rad) ranging from 1.42 to $26.62 \mathrm{kDa}$. Bands marked 1 and 2 were manually excised from the gel for tryptic digestion and MALDI-TOF/TOF analyses. ated with increases in specific IgG4, as was the case in the present study (table 1), although this is not always accompanied by decreases in total or specific IgE levels [14]. Moreover, a slow rate of change in SPT and total IgE, which only decreased significantly after 6 months of tolerance, was reported after a rush protocol (5 days) of desensitization to egg [15]. In our study, even an increase in specific IgE to whole egg, egg white and LYS was detected. Similarly, it was reported that peanut-specific IgE increased during the 1st year of peanut oral immunotherapy approximately 3 -fold after 3 months of treatment and decreased by $12-18$ months [16].

Of note, $5 \mathrm{mg}$ of LYS contained in a Lizipaina tablet caused this patient a severe allergic reaction, while during the baseline DBPCFC, at least $30 \mathrm{mg}$ of LYS contained in a single dose of $900 \mathrm{mg}$ of dehydrated egg white (corresponding to an accumulated dose of approximately 1,800 $\mathrm{mg}$ and to $60 \mathrm{mg}$ of LYS) were well tolerated. It should be mentioned that the results of skin tests and oral challenges performed to 40 egg-allergic patients demonstrated that OVO-DES maintains the same allergenicity as raw egg white, with no significant differences in the doses that led to symptoms following the positive challenges and in
Benedé et al. 
Fig. 5. Fragments released by papain following reduction with $\beta$-ME (fig. 4 ; table 2 ) are depicted in white on the 3D structure of LYS obtained from the RCSB Protein Data Bank with the UCSF Chimera package. The disulfide bonds are marked in black.
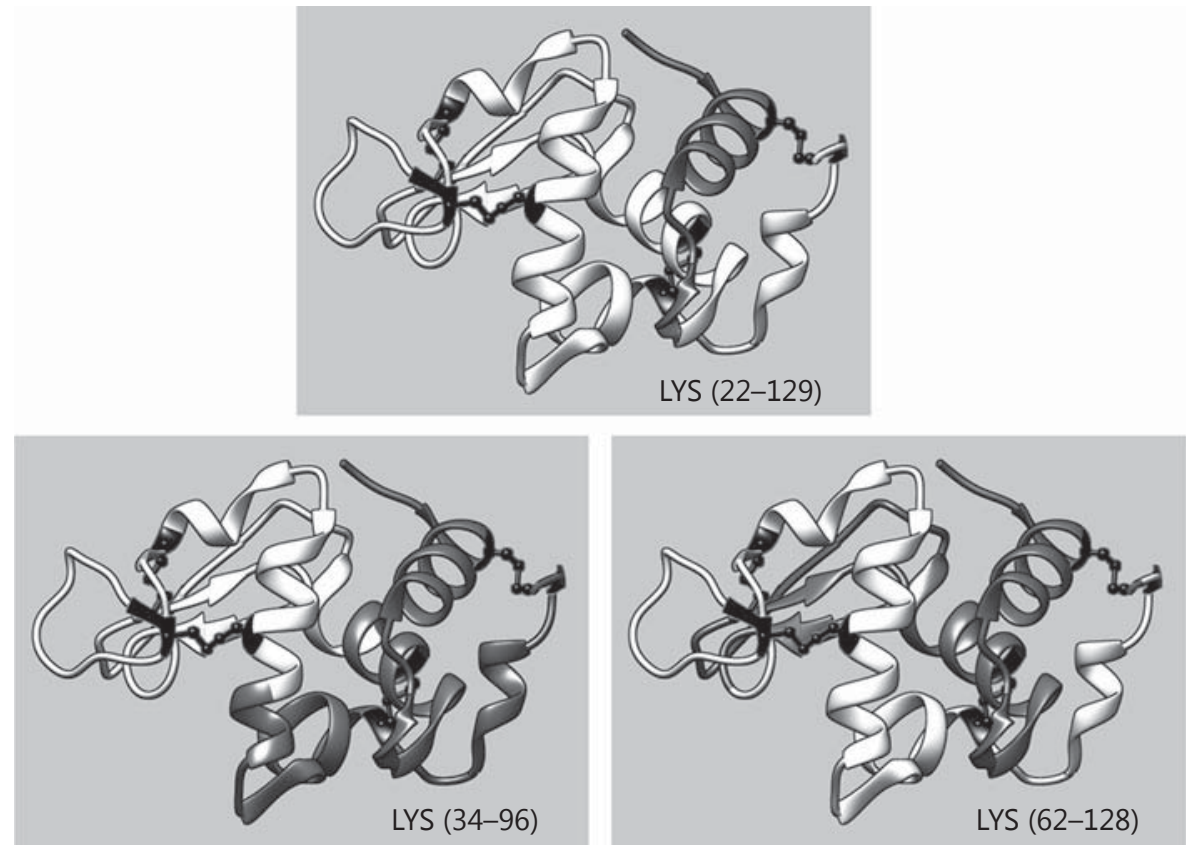

the symptoms observed [10]. This raised the possibility that the presence of papain could increase the allergenic potential of LYS.

Inhaled papain is not only a potent allergen found in occupational settings [17], papain (if enzymatically active, as is the case in other cysteine proteinases) is also able to induce Th2 responses and to exert an adjuvant effect on the sensitizing potential of other allergens, independently of its own antigenicity $[18,19]$. In addition, its proteolytic properties can enhance its mode and route of transport across epithelial barriers, which may have an impact on the immune responses generated [20]. Therefore, a role for papain in the initiation of allergic responses to LYS cannot be excluded. In fact, a case of angioedema due to the ingestion of Lizipaina was reported in a non-egg-allergic woman who was regularly eating egg [21]. On the other hand, it is also feasible that papain can increase the eliciting properties of an allergen, such as LYS, in already sensitized patients, by enhancing its bioavailability and the inflammatory response it provokes or by producing fragments with IgE binding ability. In fact, even if the individual patients tested were shown to vary in their reactivity towards papain-produced LYS fragments, qualitative results suggested that, in some of them, IgE binding to LYS hydrolyzed with papain was more intense than to an equivalent amount of intact LYS. We had previously found that pepsin digestion of LYS released peptides that carried an important epitope load, so that the IgG and IgE binding properties of the digests were maintained to a high extent [22].

Under nonreducing conditions, SDS-PAGE patterns of both LYS treated with papain and Lizipaina showed the presence of intact LYS that partially disappeared following reduction with $\beta$-ME releasing IgE-reactive fragments (fig. 3, 4). This indicated that papain degraded LYS giving rise to epitopes that could remain linked through the disulfide bonds present in the LYS molecule. MALDITOF/TOF allowed the identification of three possible IgE-binding fragments: LYS (22-129), LYS (34-96) and LYS (62-128) in the immunoreactive bands detected by Western blotting following SDS-PAGE under reducing conditions (table 2). These peptides comprised previously described IgE-binding epitopes, such as LYS (57-83) and LYS (108-122) [13]. As illustrated in figure 5, LYS (22-129) and LYS (62-128) could form part of bigger structures owing to the disulfide bonds connecting $\mathrm{Cys}_{6}-$ $\mathrm{Cys}_{127}, \mathrm{Cys}_{30}-\mathrm{Cys}_{115}, \mathrm{Cys}_{64}-\mathrm{Cys}_{80}$ and $\mathrm{Cys}_{76}-\mathrm{Cys}_{94}$, and the possibility arises that these new structures could present an enhanced allergenic potential.

A further possibility is that the administration of tablets to be dissolved slowly in the mouth could enhance pregastric absorption of LYS in the oral cavity, which would explain the occurrence of symptoms few minutes after ingestion of Lizipaina, as described in this work. Allergen absorption from the human mucosa has been demonstrated [23] and it would be worth investigating if 
it could be intensified in the presence of proteases. Actually, targeting proteolytic activity by inhibitors has shown potential for adjunct airway allergy therapy [24].

In conclusion, the combined administration of LYS with proteolytic enzymes such as papain may have developed a severe allergic reaction in the patient studied. These results underline the importance of considering all the components and their interactions when drugs are to be consumed by allergic persons.

\section{Acknowledgments}

The authors acknowledge financial support from Fundación Salud 2000 (Merck-Serono, Spain) and ALK-Abelló Laboratories (Madrid, Spain), and by the project AGL2011-24740. S. B. and I.L.E. acknowledge the financial support of CSIC through JAE-Pre and JAE-Doc grants, and D.L.-O. the financial support of the Ministerio de Educación, Cultura y Deporte through a FPU grant.

\section{References}

1 López-Exposito I, Recio I: Antibacterial activity of peptides and folding variants from milk proteins. Int Dairy J 2006;16:1294-1305.

2 Frémont S, Kanny G, Nicolas P, MoneretVautrin DA: Prevalence of lysozyme sensitization in an egg-allergic population. Allergy 1997;52:224-228.

-3 Walsh BJ, Hill DJ, Macoun P, Cairns D, Howden MEH: Detection of four distinct groups of hen egg allergens binding IgE in the sera of children with egg allergy. Allergol Immunopathol (Madr) 2005;33:183-191.

4 Iaconelli A, Fiorentini L, Bruschi S, Rossi F, Mingrone G, Piva G: Absence of allergic reaction to egg white lysozyme additive in Grana Padano cheese. J Am Coll Nutr 2008;27:326331.

-5 Weber P, Kratzin H, Brockow K, Ring J, Steinhart $\mathrm{H}$, Paschke A: Lysozyme in wine: a risk evaluation for consumers allergic to hen's egg. Mol Nutr Food Res 2009;53:1469-1477.

-6 Audicana Berasategui MT, Corominas Sánchez M, De Barrio Fernández M, García Avilés MC, García Robaina JC, Gastaminza Lasarte G, Laguna Martínez JJ, Lobera Labairu T, López San Martín M, Martín Lázaro J, Moreno Rodilla E, Ortega Rodríguez N, Torres Jaén MJ: Potential hypersensitivity due to the food or food additive content of medicinal products in Spain. J Investig Allergol Clin Immunol 2011;2:496-506.

7 Artesani MC, Donnanno S, Cavagni G, Calzone L, D’Urbano L: Egg sensitization caused by immediate hypersensitivity reaction to drug-containing lysozyme. Ann Allergy Asthma Immunol 2008;101:105.

-8 Ledesma Benítez I, Regueras Santos L, Lapeña López de Armentia S: Adverse drug reaction as the form of onset of egg sensitization. An Pediatr (Barc) 2006;38:424-425.
-9 Wills-Karp M, Nathan A, Page K, Karp CL: New insights into innate immune mechanisms underlying allergenicity. Mucosal Immunol 2010;3:104-110.

-10 Escudero C, Sánchez-García S, Rodríguez del Río P, Pator-Vargas C, García-Fernández C, Pérez-Rangel I, Ramírez-Jiménez A, Ibáñez MD: Dehydrated egg white: an allergen source for improving efficacy and safety in the diagnosis and treatment for egg allergy. Pediatr Allergy Immunol 2013;24:263-269.

11 European Academy of Allergology and Clinical Immunology (EAACI). Position Paper: immunotherapy. Allergy 1993;48(suppl): 7-35.

12 Martos G, Pineda-Vadillo C, Miralles B, Alonso-Lebrero E, López-Fandiño R, Molina E, Belloque J: Identification of an IgE reactive peptide in hen egg riboflavin binding protein subjected to simulated gastrointestinal digestion. J Agric Food Chem 2012;60:5215-5220.

13 Jiménez-Saiz R, Benedé S, Miralles B, LópezExpósito I, Molina E, López-Fandiño R: Immunological behavior of in vitro digested eggwhite lysozyme. Mol Nutr Food Res 2014;58: 614-624.

14 Burks AW, Jones, SM, Wood RA, Fleischer DM, Sicherer SH, Lindblad RW, Stablein D, Henning AK, Vickery BP, Liu AH, Scurlock AM, Shreffler WG, Plaut M, Sampson HA: Oral immunotherapy for treatment of egg allergy in children. N Engl J Med 2012;367:233243.

15 García Rodríguez R, Urra JM, Feo-Brito F, Galindo PA, Borja J, Gómez E, Lara P, Guerra F: Oral rush desensitization to egg: efficacy and safety. Clin Exp Allergy 2011;41:12891296.
16 Jones SM, Pons L, Roberts JL, Scurlock AM, Perry TT, Kulis M, Shreffler WG, Steele P, Henry KA, Adair M, Francis JM, Durham S, Vickery BP, Zhong XP, Burks AW: Clinical efficacy and immune regulation with peanut oral immunotherapy. J Allergy Clin Immunol 2009; 124:292-300.

17 Soto-Mera MT, López-Rico MR, Filgueira JF, Villamil E, Cidrás R: Occupational allergy to papain. Allergy 2000;55:983-984.

18 Sokol CL, Barton GM, Farr AG, Medzhitov R: A mechanism for the initiation of allergeninduced $\mathrm{T}$ helper type 2 responses. Nat Immunol 2008;9:310-318.

19 Cunningham PT, Elliot CE, Lenzo JC, Jarnicki AG, Larcombe AN, Zosky GR, Holt PG, Thomas WR: Sensitizing and Th2 adjuvant activity of cysteine proteinase allergens. Int Arch Allergy Immunol 2012;158:347-358.

20 Bufe A: The biological function of allergens: relevant for the induction of allergic diseases? Int Arch Allergy Immunol 1998;117:215-219.

21 Pérez-Calderón R, Gonzalo-Garijo MA, Lamilla-Yerga A, Mangas-Santos R, MorenoGaston I: Recurrent angioedema due to lysozyme allergy. J Investig Allergol Clin Immunol 2007;17:246-266.

22 Jiménez-Saiz R, Martos G, Carrillo W, LópezFandiño R, Molina E: Susceptibility of lysozyme to in-vitro digestion and immunoreactivity of its digests. Food Chem 2011;127: 1719-1726.

23 Dirks CG, Pedersen MH, Platzer MH, Bindslev-Jensen C, Skov PS, Poulsen LK: Does absorption across the buccal mucosa explain early onset of food-induced allergic systemic reactions? J Allergy Clin Immunol 2005;115: 1321-1323.

24 Saw S, Kale SL, Arola N: Serine protease inhibitor attenuates ovalbumin induced inflammation in mouse model of allergic airway disease. PLoS One 2012;7:e41107. 